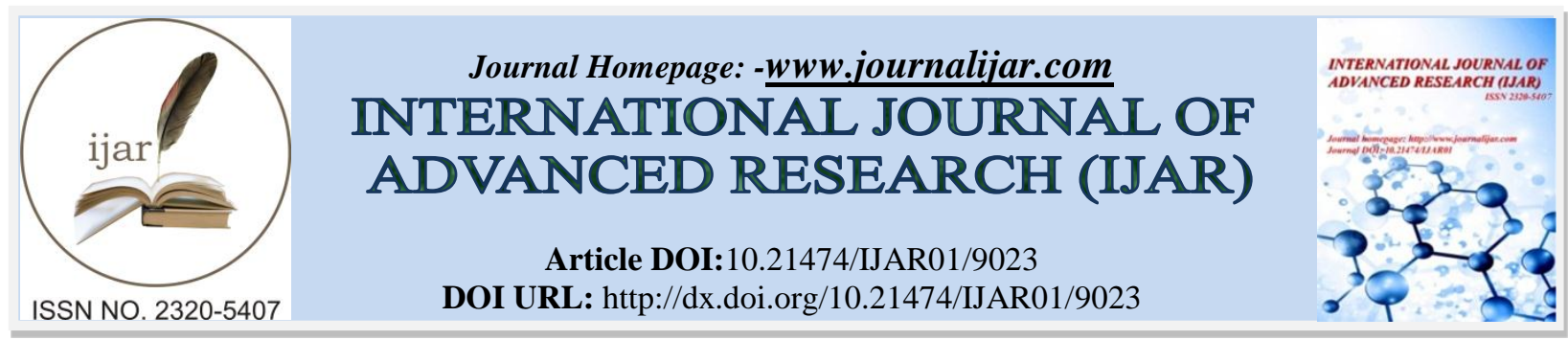

RESEARCH ARTICLE

\title{
PERFORMANCE TEST ON FOUR STROKE DIESEL ENGINE WITH MODIFIED EXHAUST SILENCER MUFFLER DESIGN.
}

\author{
S Ramu ${ }^{1}$, BR Ramesh Bapu ${ }^{2}$ and V Ramakrishnan ${ }^{3}$. \\ 1. Research Scholar, Department of Mechanical Engineering, CMJ University, Shillong, Meghalaya. \\ 2. Dean, Chennai Institute of Technology, Kundrathur, Chennai, Tamil Nadu. \\ 3. Professor, Department of Mechanical Engineering, CMJ University, Shillong, Meghalaya.
}

\section{Manuscript Info}

Manuscript History

Received: 04 March 2019

Final Accepted: 06 April 2019

Published: May 2019

Key words:-

CREO Software, Four stroke Diesel

Engine and Modified Muffler Section.

\begin{abstract}
The main objective of the study has been evaluate the performance measurement of four stroke diesel engine with modified exhaust silencer muffler design. The modified muffler designed by CERO software version 2.0 as per standard dimension in the chart and it's optimized for expected dimension. The article focused on the main characteristics of attenuation of sound wave reduction by updated design implemented on the internal cross section of muffler and experimented by the performance test on four stroke diesel engine and in addition of engine efficiency are compared with the existing model in term of brake thermal efficiency, indicated thermal efficiency, mechanical efficiency, brake specific fuel consumption, temperature and pressure measurement of the engine.
\end{abstract}

Copy Right, IJAR, 2019,. All rights reserved.

\section{Introduction:-}

There are five different design criterion in the mufflers design. These are acoustical, aero dynamical, mechanical, geometrical and economic criteria. The acoustical criterion specifies the minimum noise reduction required from the muffler as a function of frequency. A high intensity pressure wave generated by combustion in the engine cylinder propagates along the exhaust pipe and radiates from the exhaust pipe termination. The pulse repeats at the firing frequency of the engine which is defined by $\mathrm{f}=$ (engine rpm $\mathrm{x}$ number of cylinders) $/ 120$ for a four stroke engine.

Silencer is also termed as muffler. It is used for reducing the noise emitted by exhaust of an internal combustion engine, which is a major source of noise pollution. It becomes a more vital concern when used in residential areas or areas where noise creates hazard. Generally, noise level of more than 80-90 DB is injurious for human being. The performance of an exhaust system is assessed by different factors; the most important factors are backpressure and the insertion loss of the system. High backpressure in an exhaust system affects the performance of the engine, decreasing power and increasing fuel consumption, and hence emissions. The various dimensions of the muffler are varied keeping some dimensions constant and then the effect on Backpressure is observed. It can be seen that the backpressure varies nonlinearly and it cannot be predicted by any equation. It can be concluded that the backpressure value is high for small diameters as compare to bigger diameter holes even if the porosity is doubled [1].

Corresponding Author:-S Ramu.

Address:-Research Scholar, Department of Mechanical Engineering, CMJ University, Shillong, Meghalaya. 


\section{Lieterature Review}

A pollutant is a major concern to the environment releases the exhaust noise in internal combustion engine. The research articles engineers were further innovation made to maintain the environment. The engineers and researchers are focused on the part of exhaust emission and exhaust noise issues in internal combustion engine. The major issue were focused on the article [2] Paritosh Bhattacharya implemented a new design and fabrication of reactive muffler and the transmission losses was calculated in a developed muffler at $1200 \mathrm{rpm}$. It has experimented by three point method to locate at the three point inside the muffler, used to extract incoming pressure wave in front pipe and same as the transmitted wave pressure in the outlet pipe. Experimental work was cleared by as per dimension in exhaust silencer muffler chart and measurement of sound pressure level and position $45^{\circ}$. Experiment loaded in $0,50,100$, 150, $200 \mathrm{~N}-\mathrm{m}$ handled and recorded, result has compared with the chart brake power Vs transmission loss while running the engine at $1200 \mathrm{rpm}$ were identified the transmission loss increases after certain period brake power due to high pressure drop. The major problem found it on the muffler design inside the chamber. When the chamber has been complicated to release the energy, the pressure back to the engine again caused by complex structure in the muffler design. The major parameter of the internal combustion engine would not get the better performance analysis in this article. But succeeded on the implementation of new design and maintain the transmission losses $(\mathrm{dB})$ and decrease the thermal efficiency of the engine cylinder as well the basic fuel consumption is reduced compare with the existing muffler. In this article has concluded the optimal design of exhaust silencer muffler can give betterment results in the engine efficiency [2]. The research article faced on the recent technology of muffler section designed. They have concentrated internal cross section of the muffler to reduce sufficient noise within a limit, researcher handled six different experiments were arrangement of muffler design and comparison of the optimal noise level and factor of muffler to compare the perfect suit the environment reduce the noise green environment, the comparison found that dual exhaust muffler design better reduction in noise by $29.56 \mathrm{~dB}$ in study of 5HP diesel engine. The muffler design standard grade provided by ASHRAE. Four different grades design made for insertion loss (muffler grade, muffler length and muffler diameter) difference in sound level with and without muffler section attached. Some factors were considered for acoustics criterion used for muffler design. It knew that the acoustic criterion related to reduce the noise such as inlet and outlet pipe variation in dimension, benchmarking, perforation hole size etc. The graph represented of insertion loss for six muffler at variable load condition indication of grade cleared on the variation muffler 6 have gotten maximum difference than the other five muffler design. The experimental result were concluded muffler 6, 4 chamber, and dual exhaust given better result than other five muffler design [4].

\section{Experimental Work and Procedure}

3.1 Engine Specification Details for Modified Muffler Section

1. Bore

(D) $=80 \mathrm{~mm}$

2. Stroke

3. No. Cylinders

4. Engine power

5. Max. RPM

(L) $=110 \mathrm{~mm}$

$(\mathrm{n})=1$

$(\mathrm{P})=5 \mathrm{hp}$

6. Specific gravity of fuel $\quad\left(\delta_{t}\right)=0.8273 \mathrm{KJ} / \mathrm{Sec}$

7. Calorific value of fuel $\left(\mathrm{C}_{\mathrm{V}}\right)=42400 \mathrm{KJ} / \mathrm{Kg}$

8. Radius of the brake $\operatorname{drum}(\mathrm{R})=0.32 \mathrm{~m}$

\subsection{Exhaust Silencer Muffler Elliptic in Cross Section}

The research work almost similar to that of the article [3], there expressed the performance characteristic of four stroke diesel engine with modified muffler design operated by mechanical loading. The present article invented the geometrical criterion of the elliptic muffler section where identified the design, dimension and fabrication technology has completed successfully by the role and literature of the paper given optimized dimension, design and fabrication with the recent technology with the reference of best suit conclusion by the experiment in the research article referenced strong recommendation for further research [3]. The background noise was measured before starting the experiment. All engines another machines were shut down during testing of mufflers and also while measuring background noise. This is to avoid local disturbances. The meter was positioned at the same level that of flow of exhaust gas so that the noise level can be recorded effectively. The 4-stroke diesel engine was started. The readings were observed at $1500 \mathrm{rpm}$, as reactive muffler is most effective at low frequencies and different torque (loads); no load, 50 Nm, 150 Nm, 200 Nm [3]. 


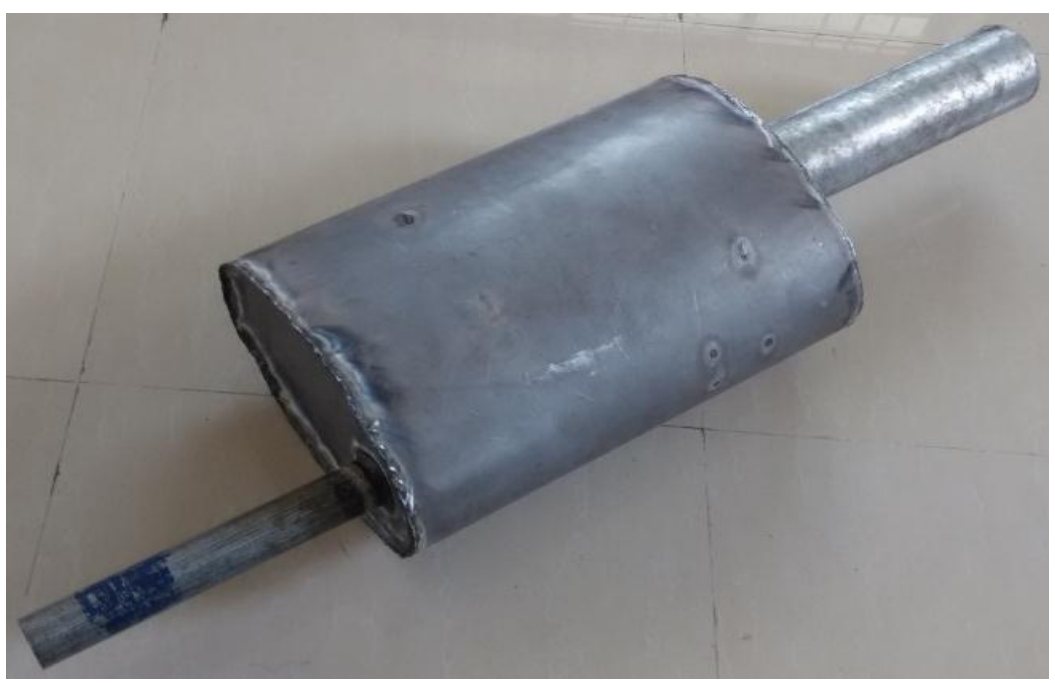

Fig 1:-Elliptic Muffler

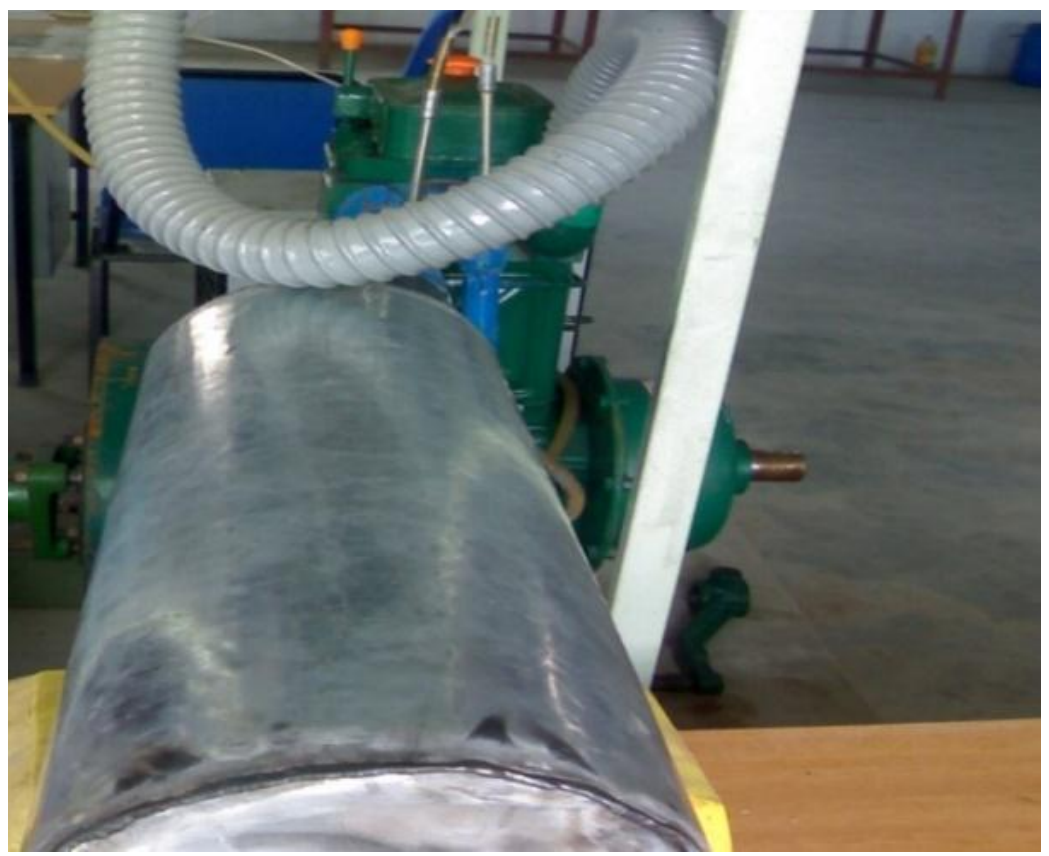

Fig 2:-Experimental Setup [3]

\section{Results and Discussion:-}

\subsection{Circular Cross Section Muffler}

[3] Already concluded about the circular cross sectional muffler made the perfect suit design and dimension of the engine, but the result did not meet the expected level. So the research work continued again the design and development were required for the completion of the project. The inventor has focused the criterions of muffler found the basement of the further development of the research since the design tool handled in AutoCAD for circular section, Pro- E and CREO 2.0 Version for modified section. The performance characteristic of four stroke diesel engine compared without muffler, existing method and modified circular muffler. The result variation described the existing developed circular muffler maintained less performance than other two methods Fig. 3, 4 and 5 . 


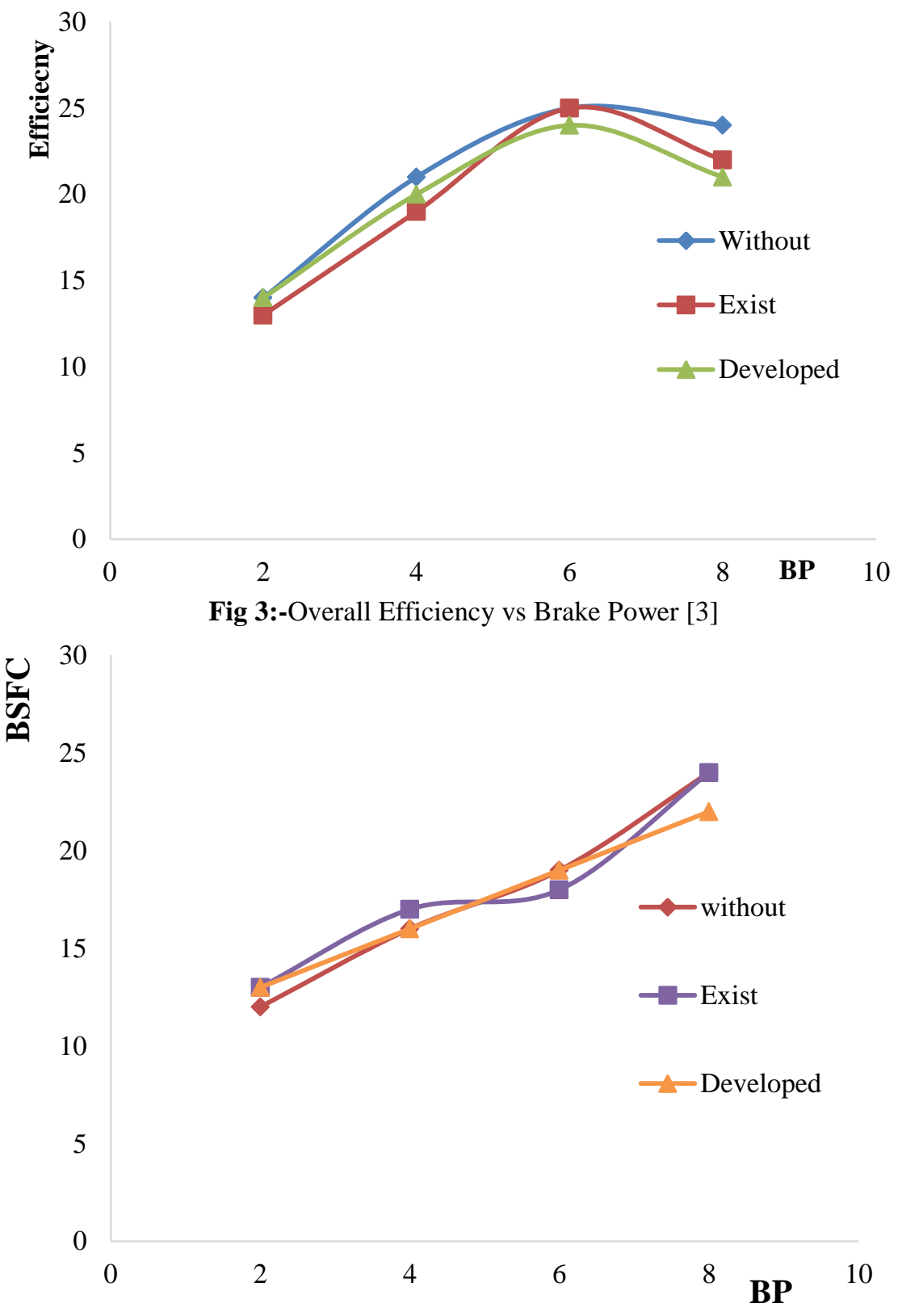

Fig 4:-Brake Specific Fuel Consumption vs Brake Power [3]

Fig 3, 4 and 5, when the engine started at the initial condition the applied load gradually increased corresponding noted the brake power and overall efficiency of the engine curve graphically represented moderate performance at certain time period. After long run of the engine and in addition of load condition, the performance of engine fluctuated where the performance characteristic of the engine deviated. 


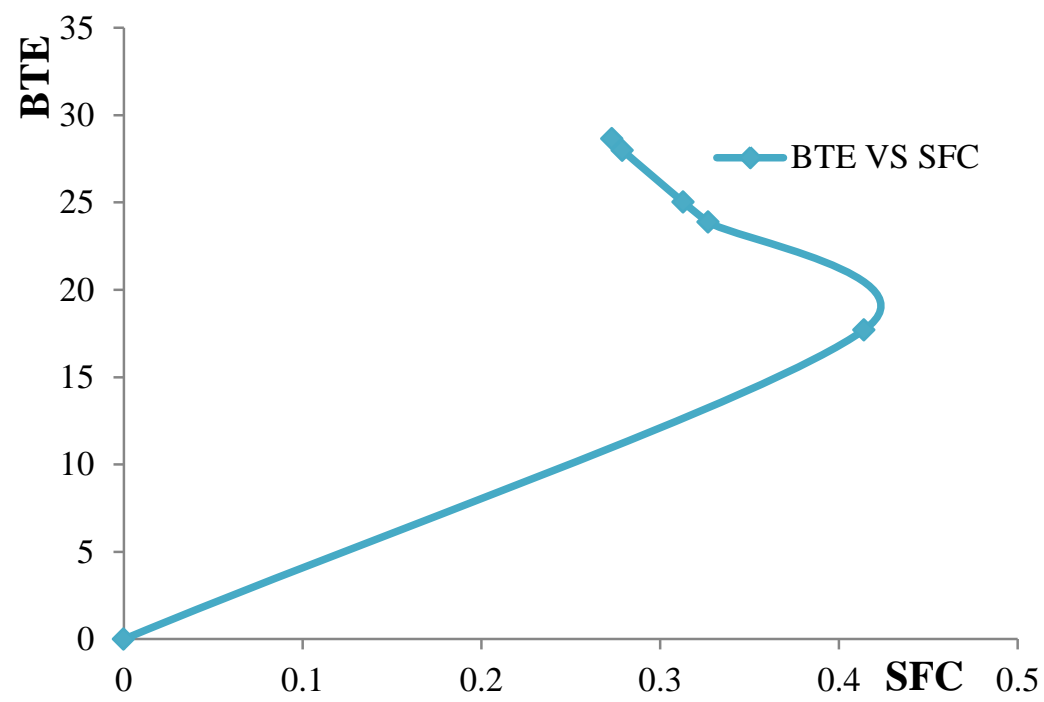

Fig 5:-Brake Thermal Efficiency vs Specific Fuel Consumption [3]

\subsection{Need to Improve the Following Factor for Modified Design}

1. Major reason focused on design and dimensions of the muffler sections.

2. Grade selection and variety of muffler configuration referred as per standard chart.

3. Design handled tools and corrections. (Software techniques are AutoCAD, Pro-E, Solidworks, CREO, and CATIA etc.)

4. Involving the concepts and principle analysis of muffler internal cross sectional design.

5. Handing fabrication technology without tolerance and outcome of the muffler dimension meet the expected design as per the final chart.

\subsection{Modified Cross Section Muffler}

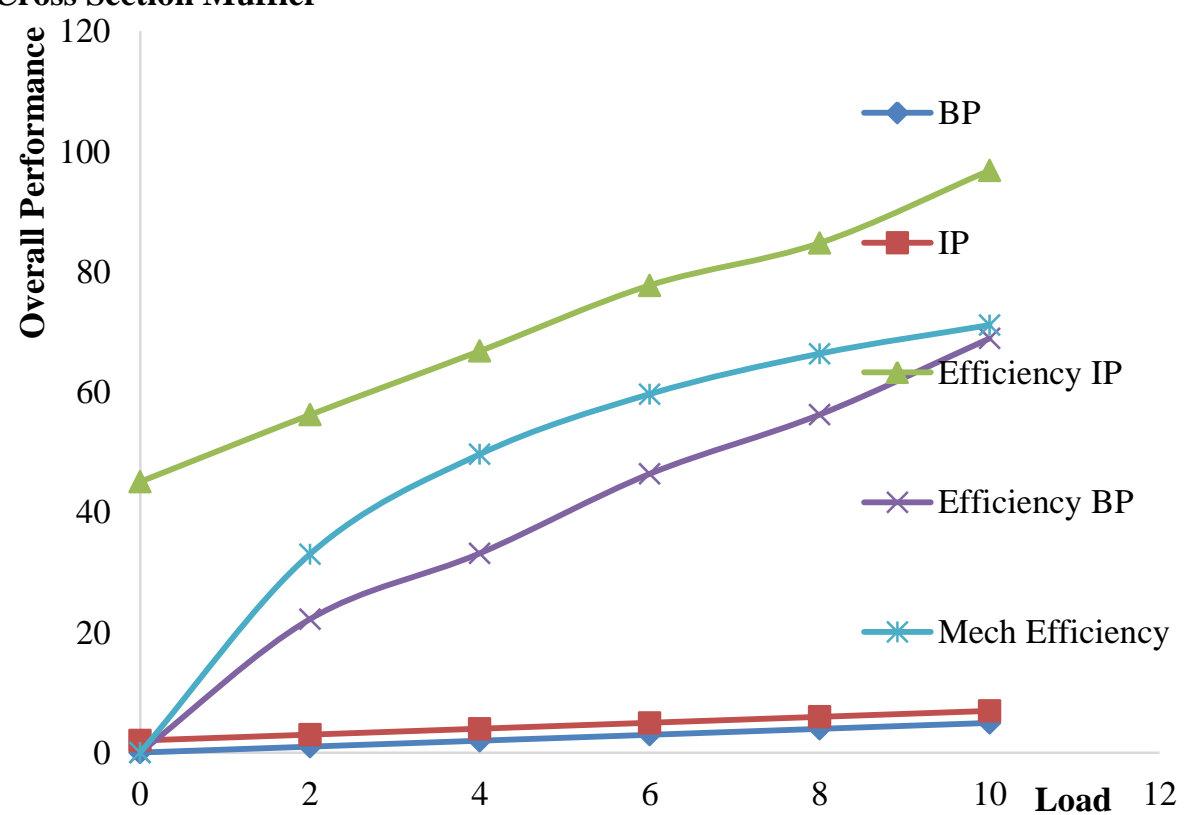

Fig 6:-Overall Performance vs Load

Figure 6, represented the performance characteristic of the four stoke diesel engine modified muffler in elliptic cross section operated by the mechanical loading. The characteristic of the graph indicated the load test on four stroke diesel engine variations in the following parameters are Brake power, Indicated power, Mechanical efficiency, and 
Indicated thermal efficiency and Brake thermal efficiency of the engine. The maximum ranges of the indicated thermal efficiency and brake thermal efficiency are $93 \%$ and $65 \%$ respectively, similarly for Mechanical efficiency reached maximum $60 \%$, the experimental procedure and recorded reading observation are similar to evaluate the performance measurement of the engine.

\section{Conclusion:-}

1. The Specific Fuel Consumption is low compared to ordinary muffler.

2. Reduction of temperature is more compared to ordinary muffler.

Thus the modified muffler reduces the temperature and fuel consumption and increases the performance of the engine. Therefore it can be suggested design for manufacturing.

\section{Reference:-}

1. Potente and Daniel, "Design principle for an automotive muffler" Proceedings of Acoustics 2005, 9-11 November 2005, Busselton, Western Australia.

2. Paritosh Bhattacharya "Transmission loss and performance test of a two cylinder four stroke diesel engine" Journal of Engineering Science and Technology, Vol. 5, No. 3 (2010) $284-292$.

3. S. Ramu, R. Srinivasan, S. Somasundaram and Tariku Achamyeleh, "Design of exhaust silencer muffler for transmission losses with the performance of a four stroke diesel engine with and without muffler section" Volume 8, Issue 1, January 2017, pp. 139-145, Article ID: IJMET_08_01_01, ISSN Print: 0976-6340 and ISSN Online: 0976-6359.

4. Yash K. Kakadiya, Prof. B.S. Patel, "Design and Comparison of Mufflers Having Different Arrangements for Diesel Engine" SSRG International Journal of Mechanical Engineering (SSRG - IJME) - Volume 4 Issue 6 June 2017, ISSN: 2348 - 8360, PP: 24-31.

5. Vaibhav D. Prajapati and Ankit J. Desai, "Design and Analysis of Automotive Muffler" International Journal of Engineering Research \& Technology (IJERT), Vol. 5 Issue 05, May-2016, ISSN: 2278-0181, IJERTV5IS050386, pp. 384-389.

6. Krunal C. Chaudhari, Prof. R.Y.Patil, Prof. N.R.Suryawanshi and Prof. S.J.Chaudhari, "Investigation of Geometrical Parameter on Performance of Muffler Using CFD Analysis" International Research Journal of Engineering and Technology (IRJET), Volume: 03 Issue: 07 | July-2016, e-ISSN: 2395 -0056, p-ISSN: 23950072.

7. Shubham Pal, Tejpreet Singh Golan, Vinod Kumar, Virag Jain, Nilesh Ramdas and O. P. Sharma, "Design of a Muffler \& Effect of Resonator length for 3 Cylinder SI Engine" IOSR Journal of Mechanical and Civil Engineering (IOSR-JMCE), e-ISSN: 2278-1684,p-ISSN: 2320-334X, Volume 11, Issue 3 Ver. VII (May- Jun. 2014), PP 85-91.

8. Namrata Agrawal and Santosh Devkare, "FEA Analysis of Two Wheeler Silencer" International Journal of Scientific Research in Science, Engineering and Technology, 2017 IJSRSET | Volume 3 | Issue 2 | Print ISSN: 2395-1990 | Online ISSN: 2394-4099.

9. L. J. Erilksson and P. T. Thawani, "Theory and practice in exhaust system design", SAE 850989, PP 257-266, 1985 . 